\title{
Synthesis and Characterization of Hierarchical Flower-Like ZnO Particles as Effective Adsorbent and Antibacterial Agent
}

\author{
Mihrican Karagöz, Gökçe Mersin, Deniz Uzunoğlu, Esma Eser, H. İbrahim Ekiz, and Ayla Özer
}

\begin{abstract}
In present work, hierarchical flower-like $\mathrm{ZnO}$ particles (FL-ZnO) were synthesized by organic-free hydrothermal route. The hexagonal structure and the formation of flower-like structure of FL-ZnO were observed by XRD and SEM analysis, respectively. The adsorption capability of FL-ZnO for the anionic (Sunset Yellow) and cationic (Malachite Green) dyes was investigated in a batch process. The effects of initial $\mathrm{pH}$, initial dye concentration, temperature, and adsorbent concentration on the studied adsorption processes were also evaluated and the results showed that the studied adsorption systems were noticeably dependent of initial $\mathrm{pH}$ in the experimental range. The adsorption mechanism was described by the equilibrium, kinetic, and mass transfer modelling. The results showed that the experimental equilibrium data for both dyestuff were fitted well to Langmuir isotherm model, the studied adsorption kinetics were in the best agreement with the pseudo second order model, both intraparticle and film diffusion were effective on the studied adsorption systems as to Weber-Morris model. Besides, the antibacterial activities of FL-ZnO for the gram negative Escherichia-coli (O157: H7) and the gram positive Listeria monocytogenes were tested.
\end{abstract}

Index Terms-Adsorption, adsorbent, antibacterial activity, hierarchical flower-like $\mathrm{ZnO}$, metal oxide materials.

\section{INTRODUCTION}

Metal oxides, semiconductor materials, have important and wide range of application areas, such as drugs delivery, optoelectronics, environmental monitoring, antibacterial applications, process control, photocatalysis, adsorption, energy storage, and so on. Among them, $\mathrm{ZnO}$ structures are the one of the most promising materials and have attracted much attention in recent years [1]-[3]. In the adsorption processes; the adsorbent properties, such as surface area, porosity, phase composition, size distribution, crystallinity, affect remarkably the adsorption capacity; so, morphology-controlled growth and synthesis of micro/nano-structures is very crucial for many applications. This purpose can be achieved with the metal oxides, whose structural properties can be effectively tuned by predisposing the shape and dimensionality [4]. In recent years, among

Manuscript received July 5, 2017; revised September 20, 2017.

Mihrican Karagöz, Gökçe Mersin, Deniz Uzunoğlu, and Ayla Özer are with the Faculty of Chemical Engineering, Mersin University, Çiftlikköy Campus, Yenişehir-Mersin TR33343, Turkey (e-mail: mihrican0133@gmail.com, denizuzunoglu4@gmail.com, ayozer@mersin.edu.tr).

Esma Eser and H. İbrahim Ekiz are with the Faculty of Food Engineering, Mersin University, Çiftlikköy Campus, Yenişehir-Mersin TR33343, Turkey (e-mail: esmaeser@mersin.edu.tr, hiekiz@gmail.com). various morphological structures, especially, micro/nano-scale hierarchical structures of snowflakes, tubes, multipods, flower-like, sheets, plate-like, windmills, sphere, and dendrites have attracted much attention due to their stunning physicochemical properties as against conventional crystal structures such as, their less agglomerated configurations, high surface areas, and permeabilities [5]. Up to today, several synthesize methods have been studied for the hierarchical structures, like template assisted sol-gel, thermal evaporation, self-assembly, microwave methods, laser induced decomposition, hydrothermal, organic-free hydrothermal, solvothermal, and chemical vapor deposition. Among these methods, the organic-free hydrothermal synthesis method has been considered an effective and suitable route due to the its some advantages of simple, cost-effective, mild, and high yields [6]. In this regard, the hierarchical flower-like $\mathrm{ZnO}$ particles (FL-ZnO) were synthesized by the facile hydrothermal method without organic solvent and were characterized by XRD, SEM, and EDX analysis. In the literature, conventional crystalline $\mathrm{ZnO}$ structures have been widely utilized as adsorbents for the removal of many pollutants [3], [7], [8]; but there is a limited number of studies about the adsorption on hierarchical $\mathrm{ZnO}$ structures and lately, the wastewater treatment studies with hierarchical $\mathrm{ZnO}$ structures have triggered investigation enthusiasm. Therefore; in this work, the synthesized flower-like $\mathrm{ZnO}$ particles were evaluated as adsorbents in the adsorption of both the anionic (Sunset Yellow) and the cationic (Malachite Green) dyestuffs, and the equilibrium, kinetics, mass transfer, and thermodynamic studies were done. Moreover, $\mathrm{ZnO}$ micro/nano-structures have antibacterial activities and are classified in a group of inorganic antimicrobial agents that are safer and very stable as against organic antibacterial agents. This case allows of $\mathrm{ZnO}$ structures to be exploited for antimicrobial applications such as in food industry, cosmetics applications, and so on [9]. Hence, the antibacterial activity of FL-ZnO was also investigated against Escherichia coli (O157: H7) and Listeria monocytogenes.

\section{Methodology}

\section{A. Synthesize and Characterization of FL-ZnO}

$2.24 \mathrm{~g}$ of $\mathrm{KOH}$, and $5.96 \mathrm{~g}$ of $\mathrm{KCl}$ were dissolved in $20 \mathrm{~mL}$ of pure water in an erlenmeyer flask and then $0.1 \mathrm{~g}$ of $\mathrm{Zn}$ powder was added to the prepared solution. The final mixture was stirred continuously for $30 \mathrm{~min}$ at room temperature. Subsequently, the mixture was transferred into a Teflon-lined 
stainless steel autoclave and then hydrothermally heated at $130{ }^{\circ} \mathrm{C}$ for $8.0 \mathrm{~h}$. Lastly, the precipitates of flower-like $\mathrm{ZnO}$ particles (FL-ZnO) were separated by centrifuge, washed several times with pure water until the $\mathrm{pH}$ of the washing water became 7.0 , dried in an oven at $80{ }^{\circ} \mathrm{C}$, and stored in closed vessels in a refrigerator at $+4{ }^{\circ} \mathrm{C}$ for the further studies [10]. The hydrothermally synthesized flower-like $\mathrm{ZnO}$ particles (FL-ZnO) were characterized by X-ray Diffractometer (XRD- Philips XPert, Netherlands), Scanning Electron Microscope (SEM- Zeiss/Supra 55, Germany), Energy Dispersive X-ray Spectroscopy (EDX- Zeiss/Supra 55 , Germany).

\section{B. Adsorption Experiments}

Malachite green (MG; $\mathrm{C}_{23} \mathrm{H}_{25} \mathrm{~N}_{2}$; 329.02 g/mol; cationic) and Sunset Yellow FCF (SY; $\mathrm{C}_{16} \mathrm{H}_{10} \mathrm{~N}_{2} \mathrm{Na}_{2} \mathrm{O}_{7} \mathrm{~S}_{2} ; 452.36$ $\mathrm{g} / \mathrm{mol}$; anionic) were used as the model pollutants in this work. The adsorption capacities of FL-ZnO for the studied dyes were investigated by the single stage adsorption process in a batch system. For adsorption experiments, firstly; the required amount of FL-ZnO was put into conical flask containing dye solution at the desired initial pHs and initial dye concentration. The conical flasks were agitated in a water bath at constant temperature for required times to accomplish adsorption equilibrium. The samples were taken at predetermined time intervals and were centrifuged to separate supernatant and solid phase. Then, to determine the residual dye, the absorbance was recorded by UV-vis spectrophotometer at $618 \mathrm{~nm}$ for MG; at 412 for SY, and the adsorbed dye amount $\left(q_{t}: \mathrm{mg} / \mathrm{g}\right)$ along with the adsorption percentage (Y: \%) were calculated as following (1) and (2), respectively:

$$
\begin{gathered}
q_{t}=\left[\left(C_{0}-C_{t}\right) / X_{0}\right] \\
Y(\%)=\left[\left(C_{0}-C_{t}\right) / C_{0}\right] \times 100
\end{gathered}
$$

where $C_{0}$ and $C_{t}(\mathrm{mg} / \mathrm{L})$ are the initial and unadsorbed dye concentrations, respectively, $X_{0}(\mathrm{~g} / \mathrm{L})$ is the adsorbent concentration.

The adsorption experiments were replicated for different initial $\mathrm{pH}$, initial dye concentration, temperature, and adsorbent concentration values.

\section{Bactericidal Test}

\section{1) Culture and inoculum preparation}

Escherichia coli (O157:H7) and Listeria monocytogenes cultures were obtained from the Microbiology Laboratory of Food Engineering Department of Mersin University. The bacterial cultures were grown on TSA slants and kept at $4^{\circ} \mathrm{C}$. Isolated colonies obtained from the TSA slants were inoculated into TSB medium. The broth culture was incubated at $37^{\circ} \mathrm{C}$ for $24 \mathrm{~h}$. The optical density of the culture was adjusted between 0.08 to 0.1 at $625 \mathrm{~nm}$ to obtain inoculum size of $1 \times 10^{7}$ colony-forming unit (CFU)/mL.

\section{2) Antibacterial activity}

The antibacterial activity was evaluated using agar plate method. Surface of agar plate (Mueller Hinton Agar) was inoculated by spreading of the test microorganism over entire surface. Then, a hole with a diameter of $6 \mathrm{~mm}$ was punched aseptically and a weight (0.025 g) of the test compound
(FL-ZnO) and $30 \mu \mathrm{L}$ sterile distilled water is introduced into the well. The Petri dishes were incubated at $37^{\circ} \mathrm{C}$ for $24 \mathrm{~h}$. The test compound diffuses into the agar and inhibited the growth of the test microorganism. The diameters of inhibition growth zones were measured with a digital caliper.

\section{RESUlTS AND DisCUSSION}

In this study, the results related to the synthesize and characterization of FL-ZnO, the determination of FL-ZnO's adsorbent properties and the description of adsorption mechanisms of the anionic and cationic dyes by FL-ZnO were presented in below sections:

\section{A. Characterization of FL-ZnO}

\section{1) XRD analysis}

A typical XRD pattern of FL-ZnO is presented in Fig. 1. All the diffraction peaks can be indexed to the hexagonal ZnO structure (JCPDS card no. 36-1451; lattice constants $a=3.249$ and $c=5.206 \AA$ ). Moreover, the high and narrow diffraction peaks show the well-crystalline of $\mathrm{ZnO}$ [1].

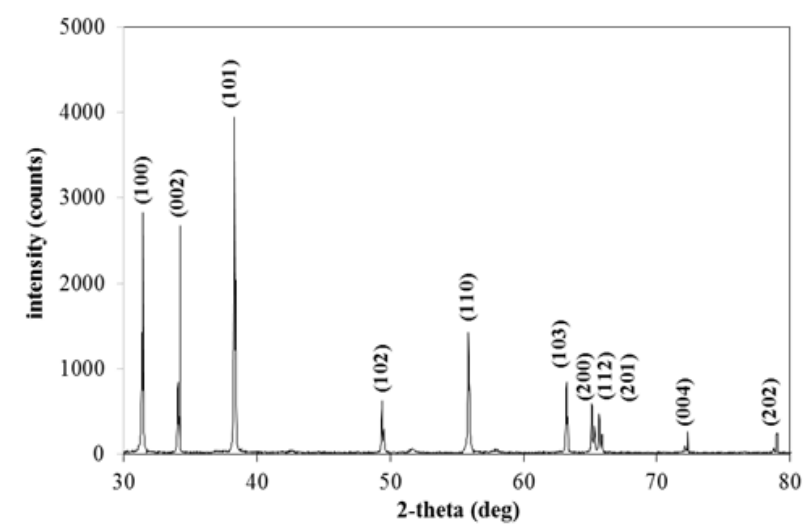

Fig. 1. XRD pattern of FL-ZnO.

\section{2) EDX analysis}

The formation of $\mathrm{ZnO}$ particles was also confirmed by EDX analysis. Fig. 2 suggested that FL-ZnO contain only the elements of $\mathrm{Zn}, \mathrm{O}, \mathrm{Pt}$, and $\mathrm{Pd}$ (the peaks of the elements of Pt and Pd stem from the coating of the sample). The atomic ratio $(\approx 1: 1)$ between $\mathrm{Zn}$ and $\mathrm{O}$ proves that the as-synthesized materials are $\mathrm{ZnO}$ particles, which is consistent with the results of XRD analysis. Also, the new peaks appearance of C, N, Na, and S after SY adsorption; C, Cl, and N after MG adsorption was determined (figure not shown), indicating the coverage of the adsorbent surface with dye molecules.

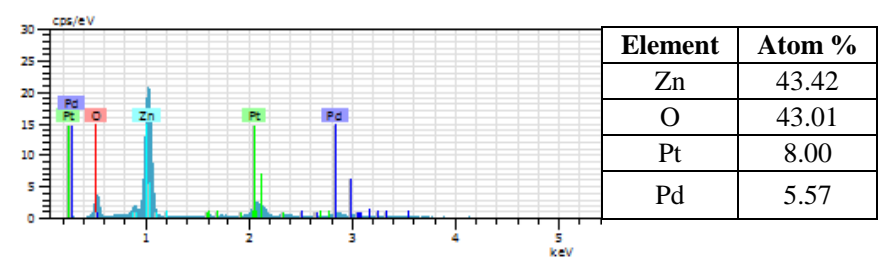

Fig. 2. EDX spectrum of FL-ZnO.

\section{3) SEM analysis}

Fig. 3 shows SEM images of FL-ZnO before and after adsorption. In the literature, the definition of the flower-like 
$\mathrm{ZnO}$ structures stems from the geometrical similarity to flowers [1]. It can be clearly seen that FL-ZnO had the typical hierarchical flower-like $\mathrm{ZnO}$ structures composed of sheets with a very porous structure. Among these sheets, there were lots of interspaces, which increased the surface area of FL-ZnO causing increase in effectiveness of them for applications as catalysts/adsorbents. Besides, Fig. 3b. showed that the pores in FL-ZnO structure were covered by dye molecules post-adsorption.

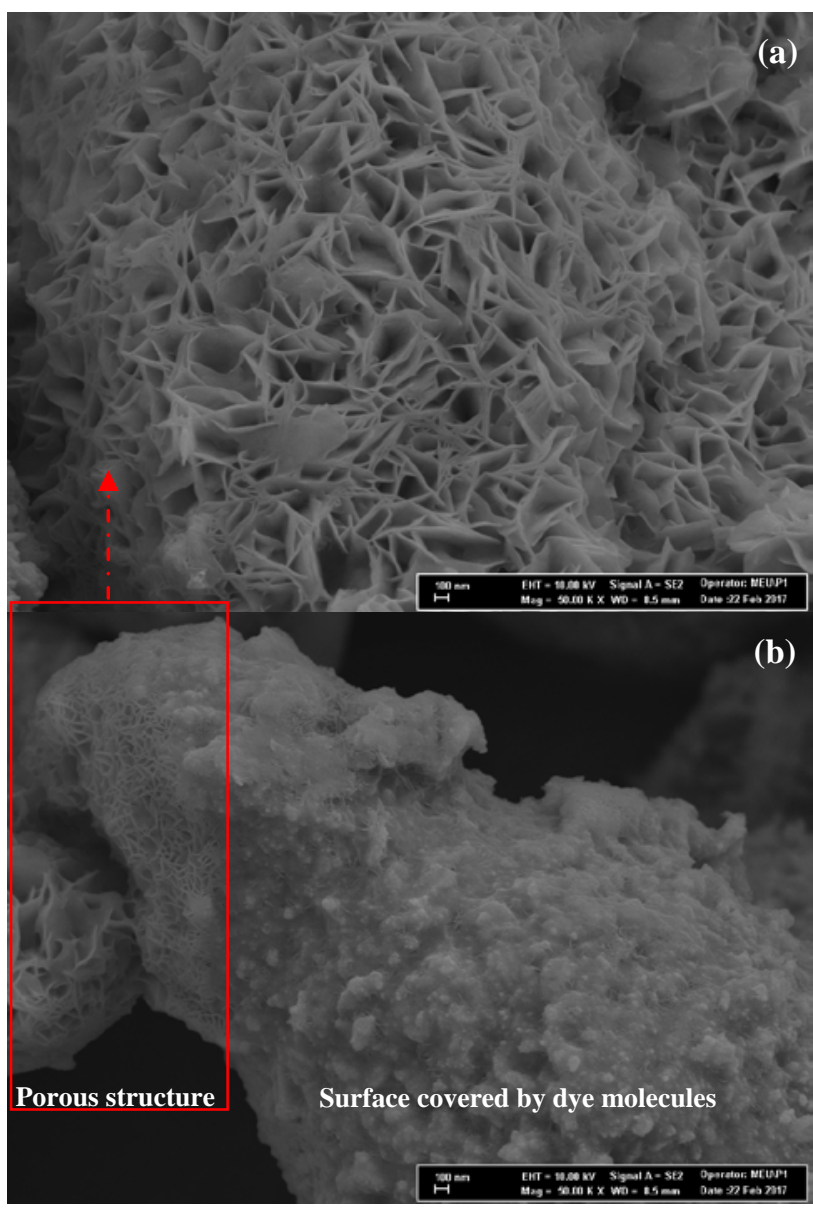

Fig. 3. SEM images of FL-ZnO before (a) and after (b) adsorption.

\section{4) Determination of point of zero charge}

The $\mathrm{pH}$ where the net surface charge is zero is called the point of zero charge $\left(\mathrm{pH}_{\mathrm{PZC}}\right)$. There are various methods like fast titration method, solid addition method, zeta-potential method, mass titration method for the determination of $\mathrm{pH}_{\mathrm{PZC}}$ In this work, $\mathrm{pH}_{\mathrm{PzC}}$ of FL-ZnO was determined by the solid addition method. Firstly, $25 \mathrm{~mL}$ of $0.1 \mathrm{M} \mathrm{KNO}_{3}$ solutions were transferred to the Erlenmeyer. Then, the $\mathrm{pH}$ values of the solutions were adjusted from 3.0 to 11 by adding $0.5 \mathrm{M}$ $\mathrm{H}_{2} \mathrm{SO}_{4}$ and/or $0.5 \mathrm{M} \mathrm{NaOH}$. After that, the required volume of $0.1 \mathrm{M} \mathrm{KNO}_{3}$ solution was added to the solutions until the total volumes of the solutions in each Erlenmeyer were 50 $\mathrm{mL}$. After the initial $\mathrm{pH}\left(\mathrm{pH}_{\mathrm{i}}\right)$ values of as-prepared solutions were then measured and exactly noted, $0.5 \mathrm{~g}$ of adsorbent was added to each Erlenmeyer. The as-prepared suspensions were manually agitated and allowed at room conditions to achieve the equilibrium for $24 \mathrm{~h}$ with intermittent manual agitation. Lastly, the final $\mathrm{pH}$ values $\left(\mathrm{pH}_{\mathrm{f}}\right)$ of the supernatants were measured and noted. The differences between the initial and final $\mathrm{pH}$ values $\left(\Delta \mathrm{pH}=\mathrm{pH}_{\mathrm{i}}-\mathrm{pH}_{\mathrm{f}}\right)$ were plotted vs. the $\mathrm{pH}_{\mathrm{i}}$ values and the plot was given in Fig. 4. By this way, $\mathrm{pH}_{\mathrm{PZC}}$ could be determined from the point intersected $\mathrm{x}$-axis. The point of zero charge $\left(\mathrm{pH}_{\mathrm{PZC}}\right)$ of $\mathrm{FL}-\mathrm{ZnO}$ was determined as 5.5. As it is known, the surface charge of material is positive at $\mathrm{pH}$ values lower than $\mathrm{pH}_{\mathrm{pzc}}$, zero at $\mathrm{pH}=\mathrm{pH}_{\mathrm{pzc}}$, and negative at $\mathrm{pH}$ values higher than $\mathrm{pH}_{\mathrm{pzc}}[11]$.

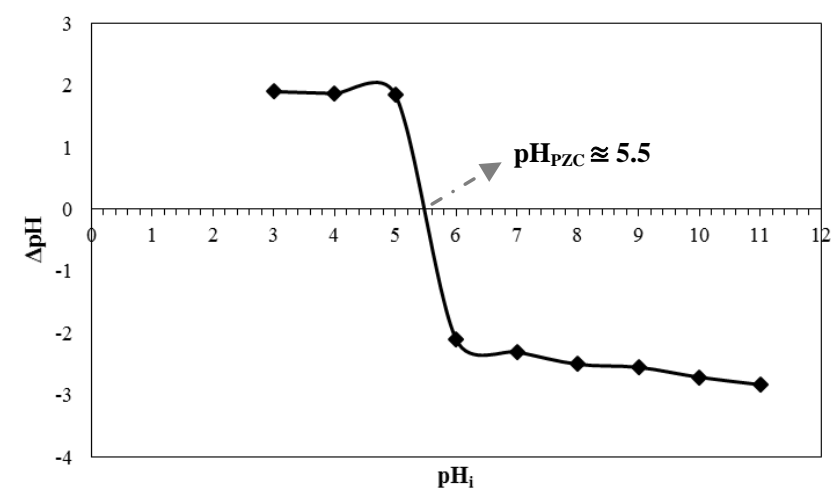

Fig. 4. Point of zero charge of FL-ZnO.

\section{B. Effects of Experimental Conditions on Adsorption of the Cationic and Anionic Dyes onto FL-ZnO}

\section{1) Effect of initial $\mathrm{pH}$}

The capability of FL-ZnO to adsorb both cationic (MG) and anionic (SY) dyestuffs can be described with the effect of initial $\mathrm{pH}$ on the studied adsorption processes. The effect of initial $\mathrm{pH}$ on the studied adsorption processes was shown in Fig 5. Accordingly, the surface of FL-ZnO at lower than $\mathrm{pH}_{\mathrm{PZC}}=5.5$ are positively charged causing high adsorption capacities for the anionic dye (SY) while the surface of FL-ZnO at higher than $\mathrm{pH}_{\mathrm{PZC}}=5.5$ are negatively charged that can easily interact with MG cations; eventually induce high adsorption capacities for both $\mathrm{SY}$ and $\mathrm{MG}$ in respect to $\mathrm{pH}_{\mathrm{PZC}}$. Consequently, it can be studied in the initial $\mathrm{pH}$ range of 2.0-5.0 for SY and 6.0-11 for MG with high removal capacities of FL-ZnO.

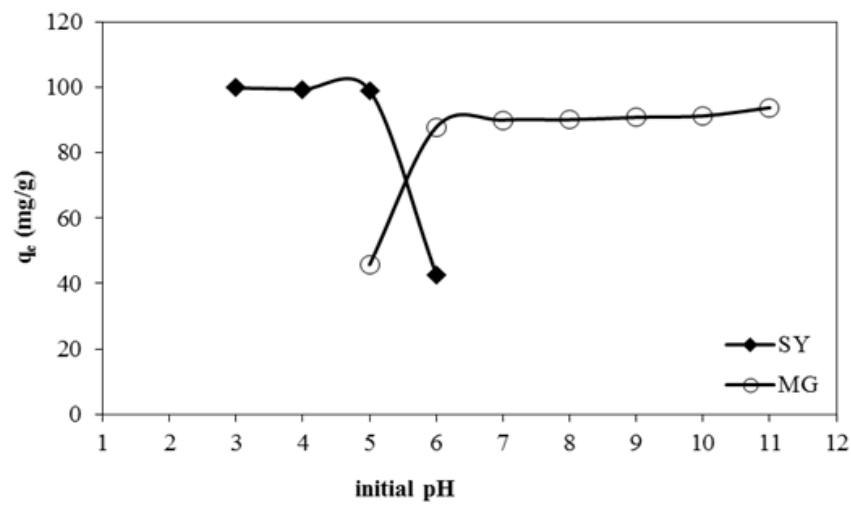

Fig. 5. Effect of initial $\mathrm{pH}(\mathrm{T}=298 \mathrm{~K}, \mathrm{C} 0=100 \mathrm{mg} / \mathrm{L}, \mathrm{X} 0=1.0 \mathrm{~g} / \mathrm{L})$.

\section{2) Effect of initial dye concentration}

Fig. 6 presents the effect on the adsorption of initial dye concentration for different initial SY and MG concentrations (25-500 mg/L). As can be seen from Fig. 5, as increasing the driving force (concentration gradient), the increase in the adsorption capacities of FL-ZnO for both dyes was linear. 
The mean of this, the waste waters with high dye concentration could be effectively purified by using FL-ZnO in a single stage purification system.

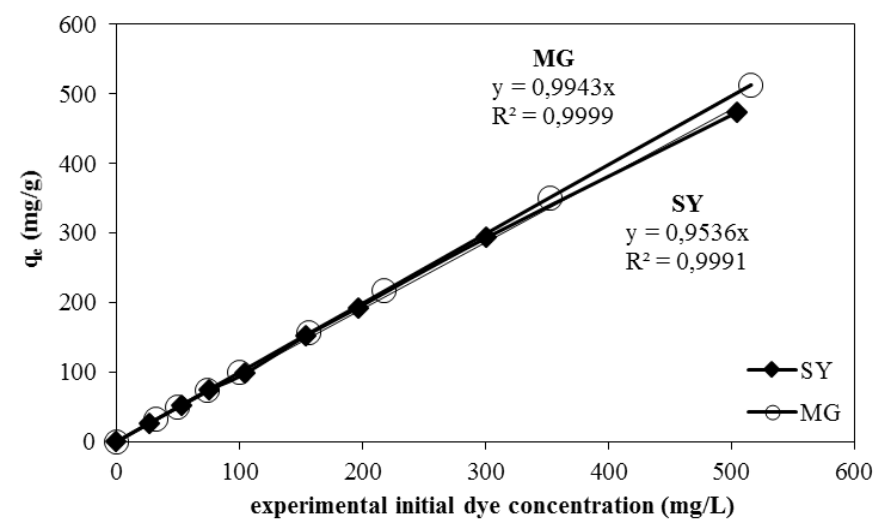

Fig. 6. Effect of initial dye concentration (initial $\mathrm{pH}=4.0$ for $\mathrm{SY}$, initial $\mathrm{pH}=8.0$ for $\left.\mathrm{MG}, T=298 \mathrm{~K}, X_{0}=1.0 \mathrm{~g} / \mathrm{L}\right)$.

\section{a) Kinetic modelling}

The information about the adsorption rate and mechanism can be provided by the pseudo first order and pseudo second order kinetic models. The linear forms of the pseudo first order and pseudo second order kinetic models were given in (3) and (4), respectively [12]:

$$
\begin{aligned}
& \log \left(q_{e}-q_{t}\right)=\log \left(q_{e}\right)-\left(k_{1 .} t / 2.303\right) \\
& \left(t / q_{t}\right)=\left(1 /\left(q_{e}{ }^{2} \cdot k_{2}\right)+\left(t / q_{e}\right)\right.
\end{aligned}
$$

where $q_{e}$ and $q_{t}(\mathrm{mg} / \mathrm{g})$ represent the adsorbed dye amounts at equilibrium and any time $(t)$, respectively, $k_{1}(1 / \mathrm{min})$ and $k_{2}$ (g/mg.min) were the rate constants of the pseudo first and the pseudo second order kinetic models, respectively.

$q_{e, \text { cal } 1}$ and $k_{1}$ can be determined from the intercept and slope of the linear plot of $\log \left(q_{e}-q_{t}\right)$ vs $t$, respectively (3) whereas $q_{e, \text { cal } 2}$ and $k_{2}$ can be determined from the slope and intercept of the linear plot of $\left(t / q_{t}\right)$ vs $t$, respectively (4).

In our study, the kinetic studies for the adsorption of SY and MG onto FL-ZnO were carried out for different initial dye concentrations and the kinetic parameters along with the related regression coefficients were presented in Table I. As can be seen from Table I, the calculated uptakes (mg/g) from the pseudo second order kinetic model are very close to the experimental uptake amounts as well as the regression coefficients of pseudo second order kinetic model are higher than the pseudo first order model. It suggested that the pseudo second order kinetic model well-described the kinetic data of the adsorption of SY and MG onto FL-ZnO rather than the pseudo first order model.

\section{b) Mass transfer modelling}

Kinetic data can be analyzed using Weber-Morris intraparticle model (W\&M), equation $q_{t}=\mathrm{Ki} \cdot \mathrm{t}^{0.5}+\mathrm{I}$. According to (W\&M) equation, a plot of $q_{t}$ versus $t^{0.5}$ is a straight line from the origin if the adsorption mechanism proceeds through the intraparticle diffusion process only. However, if the plot is linear and also has intercept value, then the process is governed by both intraparticle and film diffusion [13]. In order to evaluate the effects of the external and intraparticle diffusion on the adsorption of SY and MG onto FL-ZnO, W\&M was applied to the experimental kinetic data for different initial dye concentrations and the model parameters were given in Table II. As easily observed from Table II, both intraparticle and film diffusion were effective on the studied adsorption systems because the model plots were linear and also had intercept values.

\begin{tabular}{|c|c|c|c|c|c|c|c|}
\hline \multicolumn{8}{|c|}{ Sunset Yellow } \\
\hline \multirow{2}{*}{$C_{0, \exp }$} & \multirow[b]{2}{*}{$q_{e, \exp }$} & \multicolumn{3}{|c|}{ Pseudo first order } & \multicolumn{3}{|c|}{ Pseudo second order } \\
\hline & & $k_{1}$ & $q_{e, \text { cal1 }}$ & $R^{2}$ & $k_{2}$ & $q_{e, c a l 2}$ & $R^{2}$ \\
\hline 26.9 & 26.7 & 0.0223 & 8.5 & 0.9024 & 0.00042 & 36.0 & 0.9998 \\
\hline 52.6 & 52.2 & 0.0180 & 21.2 & 0.8344 & 0.00484 & 52.1 & 0.9983 \\
\hline 75.8 & 74.6 & 0.0128 & 19.4 & 0.7492 & 0.00590 & 74.1 & 0.9995 \\
\hline 104.7 & 98.2 & 0.0094 & 37.4 & 0.7330 & 0.00228 & 95.2 & 0.9963 \\
\hline 154.2 & 152.4 & 0.0023 & 58.8 & 0.9287 & 0.00197 & 153.8 & 0.9996 \\
\hline 196.6 & 192.9 & 0.0251 & 59.6 & 0.9523 & 0.00234 & 196.1 & 0.9998 \\
\hline 301.1 & 293.4 & 0.0166 & 164.4 & 0.7940 & 0.00038 & 294.1 & 0.9886 \\
\hline 504.7 & 473.6 & 0.0219 & 151.5 & 0.8951 & 0.00086 & 476.2 & 0.9999 \\
\hline \multicolumn{8}{|c|}{ Malachite Green } \\
\hline \multirow{2}{*}{$C_{0, \exp }$} & \multirow{2}{*}{$q_{e, \exp }$} & \multicolumn{3}{|c|}{ Pseudo first order } & \multicolumn{3}{|c|}{ Pseudo second order } \\
\hline & & $k_{1}$ & $q_{e, \text { cal1 }}$ & $R^{2}$ & $k_{2}$ & $q_{e, \text { cal } 2}$ & $R^{2}$ \\
\hline 32.3 & 32.1 & 0.00921 & 29.7 & 0.8980 & 0.00152 & 33.6 & 0.9875 \\
\hline 49.3 & 49.1 & 0.01267 & 28.1 & 0.8116 & 0.00220 & 48.8 & 0.9939 \\
\hline 73.8 & 73.6 & 0.01275 & 31.6 & 0.7871 & 0.00035 & 73.0 & 0.9979 \\
\hline 100.0 & 99.6 & 0.01359 & 48.8 & 0.7745 & 0.00150 & 99.0 & 0.9981 \\
\hline 156.5 & 155.9 & 0.01935 & 68.6 & 0.8699 & 0.00148 & 156.3 & 0.9992 \\
\hline 217.7 & 216.4 & 0.01727 & 98.0 & 0.8082 & 0.00092 & 217.4 & 0.9988 \\
\hline 352.4 & 350.9 & 0.02372 & 211.4 & 0.8975 & 0.00024 & 370.4 & 0.9948 \\
\hline 516.4 & 512.9 & 0.02027 & 195.3 & 0.8461 & 0.00048 & 526.3 & 0.9997 \\
\hline
\end{tabular}

TABLE I: THE PARAMETERS OF KINETIC MODELS

\begin{tabular}{|c|c|c|c|c|}
\hline \multicolumn{5}{|c|}{ Sunset Yellow } \\
\hline$\overline{C_{0, \exp }}$ & $q_{e, \exp }$ & $\bar{~} \boldsymbol{K}_{i}$ & II & $\overline{R^{2}}$ \\
\hline 26.9 & 26.7 & 1.9 & 14.0 & 0.9741 \\
\hline 52.6 & 52.2 & 5.1 & 20.2 & 0.9558 \\
\hline 104.7 & 98.2 & 5.9 & 46.0 & 0.9231 \\
\hline 154.2 & 152.4 & 10.0 & 74.4 & 0.9617 \\
\hline 504.7 & 473.6 & 63.5 & 150.1 & 0.9658 \\
\hline \multicolumn{5}{|c|}{ Malachite Green } \\
\hline$\overline{C_{0, \exp }}$ & $q_{e, \exp }$ & $\overline{K_{i}}$ & $\bar{I}$ & $\overline{R^{2}}$ \\
\hline 32.3 & 32.1 & 1.41 & 2.9 & 0.9905 \\
\hline 49.3 & 49.1 & 10.5 & 8.1 & 0.9875 \\
\hline 73.8 & 73.6 & 21.8 & 28.4 & 0.9475 \\
\hline 217.7 & 216.4 & 29.6 & 35.5 & 0.9657 \\
\hline 516.4 & 512.9 & 30.4 & 272.6 & 0.9333 \\
\hline
\end{tabular}

TABLE II: THE PARAMETERS OF WEBER-MORRIS MODEL

\section{3) Effect of temperature}

The effect of temperature on MG and SY adsorption onto FL-ZnO is displayed was shown in Fig. 7. It reveals that by increasing the temperature, the removal of MG increases while the adsorption of SY decreases. These cases show that the temperature was an important parameter for the studied adsorption processes. Consequently, the optimum temperature values for SY and MG adsorption onto FL-ZnO were determined to be $25{ }^{\circ} \mathrm{C}$ and $55^{\circ} \mathrm{C}$, respectively.

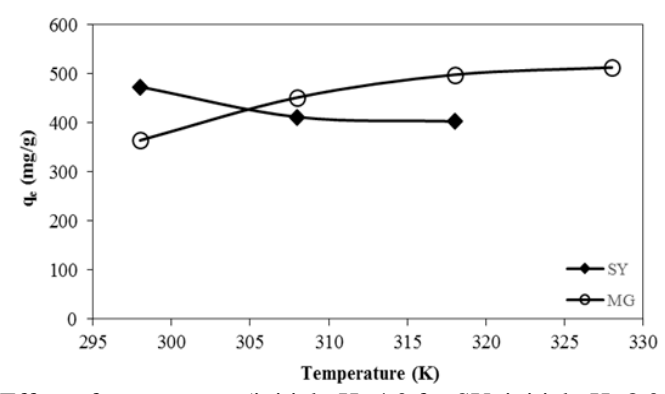

Fig. 7. Effect of temperature (initial $\mathrm{pH}=4.0$ for $\mathrm{SY}$, initial $\mathrm{pH}=8.0$ for $\mathrm{MG}$, $C_{0}=500 \mathrm{mg} / \mathrm{L}, X_{0}=1.0 \mathrm{~g} / \mathrm{L}$ ). 


\section{a) Thermodynamic study}

In order to discuss the effect of temperature on the adsorption of SY and MG onto FL-ZnO, the thermodynamic parameters including the activation energy $\left(E_{a}\right)$, entropy change $(\Delta S)$, enthalpy change $(\Delta H)$, and Gibbs energy change $(\Delta G)$ were calculated by using the following (5-7) [14]:

$$
\begin{aligned}
& \ln \left(k_{2}\right)=\ln \left(k_{o}\right)-E_{a} / \mathrm{R} T \\
& \Delta \mathrm{G}=-\mathrm{R} T \ln \left(K_{c}\right) \\
& \ln \left(K_{c}\right)=(\Delta S / R)-(\Delta H / R T)
\end{aligned}
$$

where $k_{0}$ is the Arrhenius factor, $k_{2}$ is the pseudo second order rate constant (i.e. model that best described the adsorption kinetics), $R$ is the gas constant (8.3145 J/mole.K), and $K_{c}$ is the equilibrium constant at temperature $T$. The activation energy can be determined from the slope of the linear plot of $\ln \left(k_{2}\right)$ vs $1 / T$ by using (5). The values of $\Delta \mathrm{H}$ and $\Delta \mathrm{S}$ can be obtained from the slope and intercept of the linear plot of $\ln \left(K_{c}=C_{a d, e} / C_{e}\right)$ vs $1 / T$, respectively, according to (7).

The calculated thermodynamic parameters were presented in Table III. Accordingly, the studied adsorption processes were spontaneous $(\Delta G<0)$, decreasing in randomness of adsorbed species $(\Delta S<0)$, whereas exothermic $(\Delta H<0)$ for SY adsorption and endothermic $(\Delta H>0)$ for MG adsorption. Also, if value of $\Delta H$ is lower than $84 \mathrm{~kJ} /$ mole for physical adsorption; however, if value of $\Delta H$ is in the range of $84-420 \mathrm{~kJ} / \mathrm{mole}$, then adsorption process is chemical in nature [15]. Based on $\Delta \mathrm{H}$ values, this study suggested that the adsorption of SY proceeded physically while the adsorption of MG was a

\begin{tabular}{|c|c|c|c|}
\hline \multicolumn{4}{|c|}{ Sunset Yellow } \\
\hline$T$ & $\Delta \mathbf{G}$ & $\Delta \mathbf{H}$ & $\Delta \mathbf{S}$ \\
\hline 298 & -12430.67 & \multirow{3}{*}{-55.21} & \multirow{3}{*}{-143.61} \\
\hline 308 & -10939.42 & & \\
\hline 318 & -9560.98 & & \\
\hline \multicolumn{4}{|c|}{ Malachite Green } \\
\hline$T$ & $\Delta G$ & $\Delta \mathbf{H}$ & $\Delta \mathrm{S}$ \\
\hline 298 & -2368.64 & \multirow{4}{*}{113.28} & \multirow{4}{*}{-387.516} \\
\hline 308 & -5554.32 & & \\
\hline 318 & -10478.7 & & \\
\hline 328 & -13645.7 & & \\
\hline
\end{tabular}
chemical adsorption process.

TABLE III: THERMODYNAMIC PARAMETERS

The activation energy is also widely used for differentiating between physical and chemical adsorption. The activation energy for physical adsorption usually lies from 5 to 40 $\mathrm{kJ} /$ mole due to weak forces while higher activation energies suggest chemical adsorption and its activation energy is usually in the range of $40-800 \mathrm{~kJ} / \mathrm{mole}$ [16]. The activation energies $\left(-33.25 \mathrm{~kJ} / \mathrm{mole}\right.$ with $R^{2}=0.993$ for SY; 67.54 $\mathrm{kJ} /$ mole with $\mathrm{R}^{2}=0.995$ for MG) also showed that SY removal was physical adsorption while MG adsorption process proceeded through the chemical adsorption. The positive values of $E_{a}$ indicated that increasing the temperature facilitated the adsorption or being endothermic in other words, and vice versa. Hence, SY adsorption process was exothermic whereas MG adsorption process was endothermic in nature, as can be seen from $\Delta H$ values in Table III.

\section{b) Equilibrium modelling}

In order to get information about the surface properties of adsorbent, the design of adsorption systems, and the adsorption behavior, adsorption isotherm models can be applied to experimental equilibrium data. Most frequently used isotherm model equations in linear forms, Langmuir and Freundlich, are given below:

$$
\begin{gathered}
\left(1 / q_{e}\right)=\left(1 /\left(Q_{\max } \cdot b \cdot C_{e}\right)+\left(1 / Q_{\max }\right)\right. \\
\ln \left(q_{e}\right)=\ln \left(K_{F}\right)+(1 / \mathrm{n}) \cdot\left(1 / C_{e}\right)
\end{gathered}
$$

where $q_{e}(\mathrm{mg} / \mathrm{g})$ and $C_{e}(\mathrm{mg} / \mathrm{L})$ are the adsorbed amount (solid concentration) and the unadsorbed dye concentration (liquid concentration) at the equilibrium, respectively, $Q_{\max }(\mathrm{mg} / \mathrm{g})$ is the maximum monolayer coverage adsorption capacity of adsorbent, and $b(\mathrm{~L} / \mathrm{mg})$ is the Langmuir constant about energy of adsorption, $K_{F}\left(\mathrm{mg} / \mathrm{g}(\mathrm{L} / \mathrm{mg})^{1 / n}\right)$ and $1 / \mathrm{n}$ are Freundlich model constants that representing the adsorption capacity and adsorption intensity, respectively. Langmuir isotherm model constants of $Q_{\max }$ and $b$ can be determined from the intercept and slope of the linear plot of $1 / q_{e}$ vs $1 / C_{e}$, respectively (8). Freundlich isotherm model constants of $K_{F}$ and $1 / \mathrm{n}$ can be obtained from the intercept and slope of the linear plot of $\ln \left(q_{e}\right)$ vs $\ln \left(C_{e}\right)$, respectively (9).

In this work, Langmuir and Freundlich isotherm models were evaluated for different temperature values and the calculated isotherm model constants were presented in Table IV. It was obtained that Langmuir isotherm model was determined as the best isotherm model to correlate the experimental data due to the higher $R^{2}$ and lower $\mathrm{E}$ values compared to Freundlich model. Based on the assumption of Langmuir model; active adsorption sites of FL-ZnO can be occupied by only one dye molecule at a time to form a monolayer on the adsorbent and no further adsorption can take place at that site. Moreover, it was designated from Table IV

\begin{tabular}{|c|c|c|c|c|c|c|c|c|}
\hline \multicolumn{9}{|c|}{ Sunset Yellow } \\
\hline \multirow{2}{*}{$T$} & \multicolumn{4}{|c|}{ Langmuir isotherm model } & \multicolumn{4}{|c|}{ Freundlich isotherm model } \\
\hline & $Q_{\max }$ & $b$ & $R^{2}$ & $E$ & $K_{F}$ & $1 / n$ & $R^{2}$ & $E$ \\
\hline 298 & 601.3 & 0.1212 & 0.9988 & 1.73 & 22.82 & 0.40 & 0.9571 & 12.71 \\
\hline 308 & 568.2 & 0.0221 & 0.9933 & 3.69 & 15.08 & 0.44 & 0.9660 & 5.29 \\
\hline 318 & 521.4 & 0.0233 & 0.9969 & 3.31 & 7.11 & 0.54 & 0.9669 & 5.66 \\
\hline \multicolumn{9}{|c|}{ Malachite Green } \\
\hline \multirow{2}{*}{$T$} & \multicolumn{4}{|c|}{ Langmuir isotherm model } & \multicolumn{4}{|c|}{ Freundlich isotherm model } \\
\hline & $Q_{\max }$ & b & $R^{2}$ & $E$ & $K_{F}$ & $1 / n$ & $R^{2}$ & $E$ \\
\hline 298 & 1709.4 & 0.0019 & 0.9989 & 1.98 & 4.06 & 0.909 & 0.9920 & 2.10 \\
\hline 308 & 1841.6 & 0.0029 & 0.9927 & 6.30 & 5.66 & 0.961 & 0.9869 & 7.54 \\
\hline 318 & 2008.0 & 0.0672 & 0.9936 & 6.11 & 111.51 & 0.993 & 0.8489 & 11.93 \\
\hline 328 & 2066.1 & 0.1145 & 0.9935 & 10.55 & 198.61 & 0.880 & 0.9287 & 12.04 \\
\hline
\end{tabular}
that the maximum monolayer adsorption capacities were obtained at the optimum temperature values.

TABLE IV: THE PARAMETERS OF ADSORPTION ISOTHERM MODELS FOR DIFFERENT TEMPERATURE VALUES

The comparison of the calculated maximum monolayer coverages from Langmuir isotherm model for SY and MG adsorptions of the different adsorbent types was presented in Table V. It was observed that FL-ZnO used in this study had significant high adsorption capacities, which made them to be used as very efficient adsorbents for both SY and MG removal from aqueous solutions. 
TABLE V: COMPARATIVE STUDY OF MAXIMUM ADSORPTION CAPACITY OF VARIOUS ADSORBENTS FOR SY AND MG ADSORPTION

\begin{tabular}{c|ccc}
\hline \hline Dye & Adsorbent & $\boldsymbol{Q}_{\max }$ & Reference \\
\hline \hline \multirow{5}{*}{ SY } & FL-ZnO & 601.30 & This study \\
& CaAl-LDH-NO & 398.41 & {$[17]$} \\
& Au-NP-AC & 227.27 & {$[18]$} \\
& Mg-Al-NO & 142.86 & {$[19]$} \\
& ZnO-NPs-AC & 142.85 & {$[20]$} \\
& CuS-NP-AC & 122.00 & {$[21]$} \\
& Zn(OH) 2 -NP-AC & 114.94 & {$[22]$} \\
\hline \hline \multirow{6}{*}{ MG } & FL-ZnO & 2066.10 & This study \\
& Chitosan Coated & & \\
& Bentonite Beads & & \\
& Chitosan Coated & 435.00 & {$[23]$} \\
& Bentonite Beads & & \\
& Chitosan Coated & & \\
& Bentonite Beads & & {$[24]$} \\
& Fe $\mathrm{O}_{4} @ S i \mathrm{O}_{2}-\mathrm{GO}$ & 404.86 & {$[25]$} \\
& ZnO-NP-AC & 322.58 & {$[26]$} \\
& AC/CoFe $\mathrm{O}_{4}$ & 89.29 & {$[27]$} \\
& Treated ginger waste & 84.03 & {$[28]$} \\
\hline \hline
\end{tabular}

\section{4) Effect of adsorbent concentration}

Type and concentration of adsorbent to be used in an adsorption process was very important because the adsorption take place on the active sites on surface and interior pores of the solid adsorbent. The effect of adsorbent concentration on the adsorption of SY and MG onto FL-ZnO was studied for different adsorbent concentrations and the results were shown in Fig. 8. It can be seen from Fig. 8, the adsorbed dye amounts at equilibrium decreases with increasing adsorbent concentration and the adsorption percentages remain nearly constant. The decrease in the adsorbed dye amounts at equilibrium at higher than $0.5 \mathrm{~g} / \mathrm{L}$ of adsorbent concentration could be explained as a consequence of a partial aggregation of adsorbent, which results in a decrease in effective surface area for dye removal [29]. Therefore, the optimum adsorbent concentration was selected as $0.5 \mathrm{~g} / \mathrm{L}$ for both SY and MG adsorption systems.

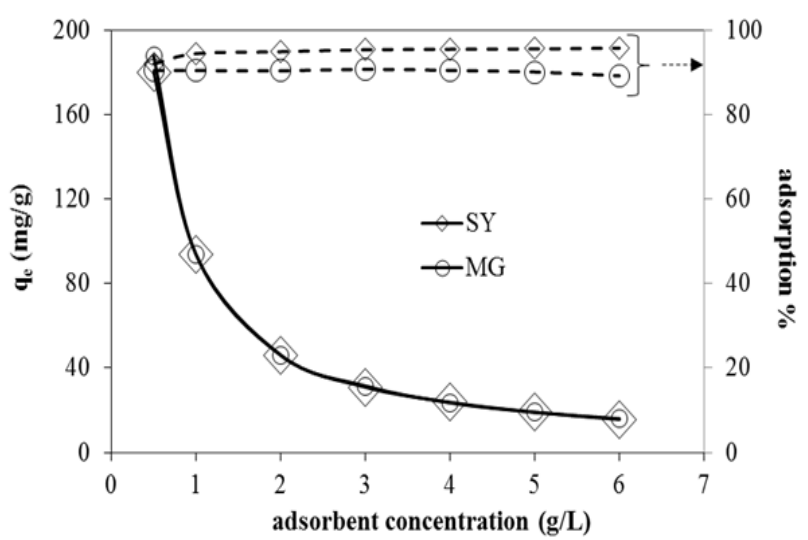

Fig. 8. Effect of adsorbent concentration (initial $\mathrm{pH}=4.0$ and $T=298 \mathrm{~K}$ for SY, initial $\mathrm{pH}=8.0$ and $T=318 \mathrm{~K}$ for $\left.\mathrm{MG}, C_{0}=100 \mathrm{mg} / \mathrm{L}\right)$.

\section{Antibacterial Activity of FL-ZnO}

FL-ZnO was effective against $E$. coli and L. monocytogenes, and the inhibition zone diameters of test compound for these bacteria $15.55 \pm 0.74$ and $20.11 \pm 0.73 \mathrm{~mm}$, respectively. This result indicated that a mixture of water and FL-ZnO had stronger inhibitory effects on growth of $L$. monocytogenes than E. coli (Fig. 9).

Previous studies on the antibacterial behavior of FL-ZnO have shown that the morphology and oxidative stress play important roles in the antibacterial activity [30].

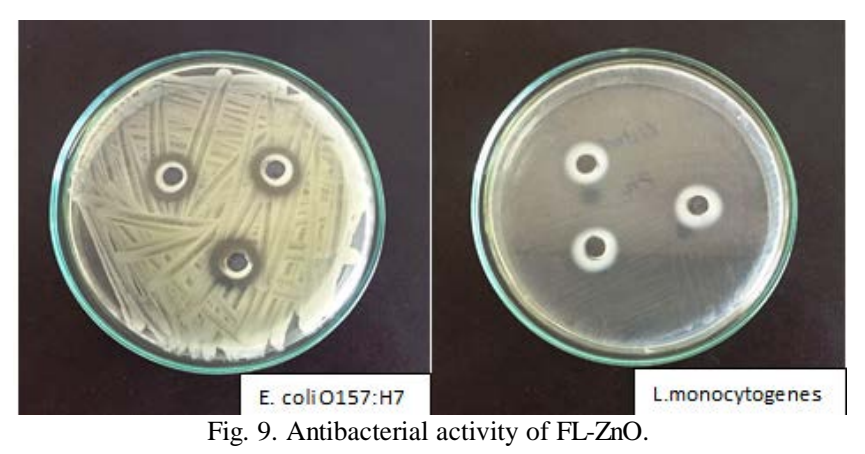

\section{CONCLUSION}

Characterization of the hierarchical flower-like $\mathrm{ZnO}$ particles (FL-ZnO) synthesizing by the facile hydrothermal method was done by XRD, SEM, and EDX analysis. FL-ZnO particles were evaluated as a potential adsorbent for removal of anionic SY dye and cationic MG dye by adsorption method from aqueous solutions and the maximum monolayer coverage capacities at optimum temperature were determined as 601.3 $\mathrm{mg} / \mathrm{g}$ for SY and $2066.1 \mathrm{mg} / \mathrm{g}$ for MG dyes. These capacities were very high compared to the other adsorbents in the literature. It confirmed that FL-ZnO particles may be used as effective adsorbent in small scale dyeing unit using batch or stirred-tank flow reactors and it can be concluded that it is enable to adsorb both anionic and cationic dyes from binary solutions by using one adsorbent. Besides, FL-ZnO particles were evaluated as an antibacterial agent and the results demonstrated that they could be successfully used as effective antimicrobial agents in agricultural and food packaging applications to control the growth of pathogenic bacteria. Consequently, our findings open the possibility of synthesizing effective adsorbent and antibacterial agent material with outstanding properties for dye removal and antibacterial applications. In addition, we suggest that the synthesis method in this study, organic-free hydrothermal route, can be extended to synthesize novel nano/micro-structures with different metals/metal oxides to explore more applications.

\section{NOMENCLATURE}

$1 / n$ a constant of Freundlich isotherm model related to adsorption intensity

$b$ a constant of Langmuir isotherm model ( $\mathrm{L} / \mathrm{mg})$

$C_{a d, e}$ concentration of adsorbed dye at equilibrium (mg/L)

$C_{e} \quad$ concentration of residual dye at equilibrium (mg/L)

$C_{t} \quad$ concentration of residual dye at $\mathrm{t}$ time $(\mathrm{mg} / \mathrm{L})$

$C_{0, \exp }$ experimental initial concentration of dye $(\mathrm{mg} / \mathrm{L})$

$E_{a} \quad$ Activation energy ( $\left.\mathrm{kJ} / \mathrm{mole}\right)$

$k_{0} \quad$ Arrhenius factor

$k_{1} \quad$ a rate constant of pseudo first order kinetic model (1/min) 
$k_{2} \quad$ a rate constant of pseudo second order kinetic model (g/(mg min))

$K_{c} \quad$ equilibrium constant

$K_{F} \quad$ a constant of Freundlich isotherm model $\left.(\mathrm{mg} / \mathrm{g}) /(\mathrm{L} / \mathrm{mg})^{1 / \mathrm{n}}\right)$

$K_{i} \quad$ Weber-Morris model constant related to intraparticle diffusion (mg/g.min ${ }^{0.5}$ )

I intercept value of Weber-Morris plot

$q_{e} \quad$ adsorbed mass per gram of adsorbent at equilibrium (mg/g)

$q_{e, \text { cal1 }}$ adsorbed mass per gram of adsorbent calculated from pseudo first order kinetic model (mg/g)

$q_{e, \text { cal2 }}$ adsorbed mass per gram of adsorbent calculated from pseudo second order kinetic model (mg/g)

$q_{e, \text { exp }}$ experimental adsorbed mass per gram of adsorbent at equilibrium (mg/g)

$q_{t} \quad$ adsorbed mass per gram of adsorbent at t time (mg/g)

$Q_{\max }$ maximum monolayer coverage capacity of adsorbent obtained from Langmuir isotherm model (mg/g)

$X_{0} \quad$ adsorbent concentration (g/L)

$R^{2} \quad$ Regression coefficient

$T$ temperature $\left({ }^{\circ} \mathrm{C}, \mathrm{K}\right)$

$t$ time (min)

$\Delta \mathrm{G} \quad$ change of Gibb's energy ( $\mathrm{J} / \mathrm{mole})$

$\Delta \mathrm{H}$ change of enthalpy ( $\mathrm{J} / \mathrm{mole})$

$\Delta \mathrm{S} \quad$ change of entropy (J/mole.K)

\section{REFERENCES}

[1] H. Zhang, D. Yang, X. Ma, Y. Ji, J. Xu, and D. Que, "Synthesis of flower-like $\mathrm{ZnO}$ nanostructures by an organic-free hydrothermal process," Nanotech., vol. 15, no. 5, pp. 622, June 2004.

[2] M. Ahmad, S. Yingying, A. Nisar, H. Sun, W. Shen, M. Wei, and J. Zhu, "Synthesis of hierarchical flower-like $\mathrm{ZnO}$ nanostructures and their functionalization by Au nanoparticles for improved photocatalytic and high performance Li-ion battery anodes,” J. Mater. Chem., vol. 21, no. 21, pp. 7723-7729, March 2011.

[3] F. Zhang, J. Lan, Y. Yang, T. Wei, R. Tan, and W. Song, "Adsorption behavior and mechanism of methyl blue on zinc oxide nanoparticles," $J$. Nanopart. Res., vol. 15, no. 11, pp. 2034-2035, October 2013.

[4] G. Tian, Y. Chen, W. Zhou, K. Pan, C. Tian, X. R. Huang, and H. Fu, "3D hierarchical flower-like $\mathrm{TiO}_{2}$ nanostructure: Morphology control and its photocatalytic property," Cryst. Eng. Comm., vol. 13, no. 8, pp. 2994-3000, February 2011.

[5] X. Luo, Z. Lou, L. Wang, X. Zheng, and T. Zhang, "Fabrication of flower-like $\mathrm{ZnO}$ nanosheet and nanorod-assembled hierarchical structures and their enhanced performance in gas sensors," New $J$. Chem., vol. 38, no. 1, pp. 84-89, October 2013.

[6] H. Zhang, R. Wu, Z. Chen, G. Liu, Z. Zhang, and Z. Jiao, "Self-assembly fabrication of 3D flower-like $\mathrm{ZnO}$ hierarchical nanostructures and their gas sensing properties," Cryst. Eng. Comm., vol. 14, no. 5, pp. 1775-1782, November 2011.

[7] C. Lei, M. Pi, C. Jiang, B. Cheng, and J. Yu, "Synthesis of hierarchical porous zinc oxide $(\mathrm{ZnO})$ microspheres with highly efficient adsorption of Congo red,” J. Colloid. Interface Sci., vol. 490, 242-251, March 2017.

[8] C. Pei, G. Han, Y. Zhao, H. Zhao, B. Liu, L. Cheng, and S. Liu, "Superior adsorption performance for triphenylmethane dyes on 3D architectures assembled by $\mathrm{ZnO}$ nanosheets as thin as $1.5 \mathrm{~nm}$," $J$. Hazard. Mater., vol. 318, pp. 732-741, November 2016.

[9] A., Sirelkhatim, S. Mahmud, A. Seeni, N. H. M. Kaus, , L. C. Ann, S. K. M. Bakhori, and D. Mohamad, "Review on zinc oxide nanoparticles: antibacterial activity and toxicity mechanism," Nano-Micro Lett., vol. 7, no. 3, pp. 219-242, July 2015.

[10] M. Feng, W. You, Z. Wu, Q. Chen, and H. Zhan, "Mildly alkaline preparation and methylene blue adsorption capacity of hierarchical flower-like sodium titanate,” ACS Appl. Mater. Interfaces., vol. 5, no. 23, pp. 12654-12662, November 2013.

[11] D. Uzunoğlu and A. Özer, "Adsorption of Acid Blue 121 dye on fish (Dicentrarchus labrax) scales, the extracted from fish scales and commercial hydroxyapatite: Equilibrium, kinetic, thermodynamic, and characterization studies,” Desalin. Water Treat., vol. 57, vol. 30, pp. 14109-14131, July 2015.

[12] Y. Li, Q. Du, T. Liu, X. Peng, J. Wang, J. Sun, and L. Xia, "Comparative study of methylene blue dye adsorption onto activated carbon, graphene oxide, and carbon nanotubes,” Chem. Eng. Res. Des., vol. 91, no. 2, pp. 361-368, February 2013.

[13] W. J. Weber Jr. and J. C. Morris, "Kinetics of adsorption on carbon from solution,” J. Sanit. Eng. Div. Am. Soc. Civ. Eng., vol. 89, pp. 31-59, 1963.

[14] A. A. Babaei, A. Khataee, E. Ahmadpour, M. Sheydaei, B. Kakavandi, and Z. Alaee, "Optimization of cationic dye adsorption on activated spent tea: Equilibrium, kinetics, thermodynamic and artificial neural network modeling," Korean J. Chem. Eng., vol. 33, no. 4, pp. 1352-1361, April 2016.

[15] E. Alver and A. Ü. Metin, "Anionic dye removal from aqueous solutions using modified zeolite: Adsorption kinetics and isotherm studies," Chem. Eng. J., vol. 200, pp. 59-67, August 2012.

[16] A. A. El-Bindary, A. Z. El-Sonbati, A. A. Al-Sarawy, K. S. Mohamed, and M. A. Farid, "Adsorption and thermodynamic studies of hazardous azocoumarin dye from an aqueous solution onto low cost rice straw based carbons,” J. Mol. Liq., vol. 199, pp. 71-78, November 2014.

[17] F. P. de Sá, B. N. Cunha, and L. M. Nunes, "Effect of pH on the adsorption of sunset yellow FCF food dye into a layered double hydroxide (CaAl-LDH-NO ${ }_{3}$ )," Chem. Eng. J., vol. 215, pp. 122-127, January 2013

[18] M. Ghaedi, F. Mohammdi, and A. Ansari, "Gold nanoparticles loaded on activated carbon as novel adsorbent for kinetic and isotherm studies of methyl orange and sunset yellow adsorption," J. Dispers. Sci. Technol., vol. 36, no. 5, pp. 652-659, April 2014.

[19] A. H. A. Malek and Y. Yasin, "Use of layered double hydroxides to remove sunset yellow FCF dye from aqueous solution,” Chem. Sci. Trans., vol. 1, no. 1, pp. 194-200, May 2012.

[20] M. Maghsoudi, M. Ghaedi, A. Zinali, A. M. Ghaedi, and M. H. Habibi, "Artificial neural network (ANN) method for modeling of sunset yellow dye adsorption using zinc oxide nanorods loaded on activated carbon: Kinetic and isotherm study,” Spectrochimica Acta. Part A, vol. 134, pp. 1-9, January 2015

[21] S. Khodadoust, M. Ghaedi, R. Sahraei, and R. A. Daneshfar, "Application of experimental design for removal of sunset yellow by copper sulfide nanoparticles loaded on activated carbon,” J. Ind. Eng. Chem., vol. 20, no. 5, pp. 2663-2670, September 2014.

[22] M. Roosta, M. Ghaedi, R. Sahraei, and M. K. Purkait, "Ultrasonic assisted removal of sunset yellow from aqueous solution by zinc hydroxide nanoparticle loaded activated carbon: Optimized experimental design,” Mater. Sci. Eng. C, vol. 52, pp. 82-89, July 2015.

[23] W. Ngah, W. Saime, N. F. M. Ariff, A. Hashim, and M. A. K. M. Hanafiah, "Malachite green adsorption onto chitosan coated bentonite beads: Isotherms, kinetics and mechanism," Clean: Soil, Air, Water, vol. 38, no. 4, pp. 394-400, February 2010.

[24] J. Zhang, M. Liu, Z. Liu, T. Yang, Q. He, K. Yang, and H. Wang, "Studies of malachite green adsorption on covalently functionalized $\mathrm{Fe}_{3} \mathrm{O}_{4} @ \mathrm{SiO}_{2}$-graphene oxides core-shell magnetic microspheres,” $J$. Sol-Gel Sci. Technol., vol. 82, no. 2, pp. 424-431, January 2017.

[25] M. Ghaedi, A. Ansari, M. H. Habibi, and A. R. Asghari, "Removal of malachite green from aqueous solution by zinc oxide nanoparticle loaded on activated carbon: Kinetics and isotherm study,” J. Ind. Eng. Chem., vol. 20, no. 1, pp. 17-28, January 2014.

[26] L. Ai, H. Huang, Z. Chen, X. Wei, and J. Jiang, "Activated carbon/ $\mathrm{CoFe}_{2} \mathrm{O}_{4}$ composites: Facile synthesis, magnetic performance and their potential application for the removal of malachite green from water,” Chem. Eng. J., vol. 156, no. 2, pp. 243-249, January 2010.

[27] R. Ahmad and R. Kumar, "Adsorption studies of hazardous malachite green onto treated ginger waste,” J. Environ. Manage., vol. 91, no. 4, pp. 1032-1038, April 2010.

[28] P. Saha, S. Chowdhury, S. Gupta, and I. Kumar, "Insight into adsorption equilibrium, kinetics and thermodynamics of malachite green onto clayey soil of Indian origin,” Chem. Eng. J., vol. 165, no. 3, pp. 874-882, December 2010.

[29] N. Barka, M. Abdennouri, and M. E. Makhfouk, "Removal of methylene blue and eriochrome black $\mathrm{T}$ from aqueous solutions by biosorption on scolymus hispanicus L.: Kinetics, equilibrium and thermodynamics," J. Taiwan Inst. Chem. E., vol. 42, no. 2, pp. 320-326, March 2011.

[30] G. R. Navale, M. Thripuranthaka, D. J. Late, and S. S. Shinde, "Antimicrobial activity of $\mathrm{ZnO}$ nanoparticles against pathogenic bacteria and fungi,” JSM Nanotechnol. Nanomed., vol. 3, pp. 1033, May 2015 


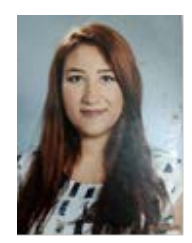

Esma Eser is a $\mathrm{PhD}$ candidate at Department of Food Engineering in Mersin University, in Turkey. Her research interests are food microbiology and biosensors for rapid microbiological analysis.

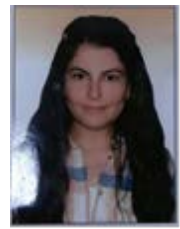

Gökçe Mersin is an undergraduate student at the Department of Chemical Engineering in Mersin University, in Turkey. She studied on dye adsorption, synthesis and characterization of adsorbent for her graduation thesis.

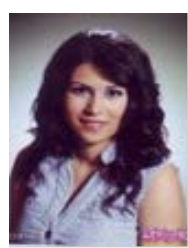

Deniz Uzunoğlu is a $\mathrm{PhD}$ candidate at Department of Chemical Engineering in Mersin University, in Turkey. Her research activities are in the area of wastewater treatment, adsorption, kinetic modelling, nanomaterials, and material characterization.

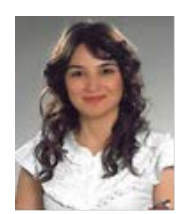

Esma Eser is a $\mathrm{PhD}$ candidate at Department of Food Engineering in Mersin University, in Turkey. Her research interests are food microbiology and biosensors for rapid microbiological analysis.

H. İbrahim Ekiz is graduated from Chemical Engineering Department of Hacettepe University, in Turkey. He is a professor of food engineering at Mersin University. His research interests are food engineering unit operations, food process design and adsorption.

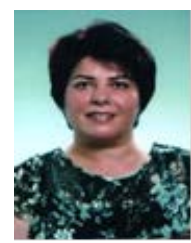

Ayla Özer is a professor of chemical engineering at the Department of Chemical Engineering in Mersin University, in Turkey. She is also working as the head of this department. Her research activities are in the area of wastewater treatment, adsorption, kinetic modelling, nanomaterials, and material characterization. 